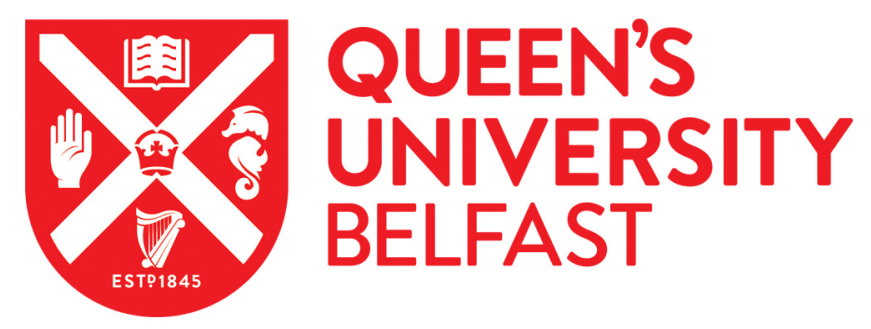

\title{
Lifestyle factors and small intestine adenocarcinoma risk: a systematic review and meta-analysis.
}

\author{
Bennett, C. M., Coleman, H. G., Veal, P. G., Cantwell, M. M., Lau, C. C. L., \& Murray, L. J. (2015). Lifestyle \\ factors and small intestine adenocarcinoma risk: a systematic review and meta-analysis. Cancer Epidemiology, \\ 39(3), 265-273. https://doi.org/10.1016/j.canep.2015.02.001
}

Published in:
Cancer Epidemiology

Document Version:

Peer reviewed version

Queen's University Belfast - Research Portal:

Link to publication record in Queen's University Belfast Research Portal

Publisher rights

(C) 2015, Elsevier. Licensed under the Creative Commons Attribution-NonCommercial-NoDerivatives 4.0 International

$\mathrm{http}: / /$ creativecommons.org/licenses/by-nc-nd/4.0/ which permits distribution and reproduction for non-commercial purposes, provided the author and source are cited.

\section{General rights}

Copyright for the publications made accessible via the Queen's University Belfast Research Portal is retained by the author(s) and / or other copyright owners and it is a condition of accessing these publications that users recognise and abide by the legal requirements associated with these rights.

\section{Take down policy}

The Research Portal is Queen's institutional repository that provides access to Queen's research output. Every effort has been made to ensure that content in the Research Portal does not infringe any person's rights, or applicable UK laws. If you discover content in the Research Portal that you believe breaches copyright or violates any law, please contact openaccess@qub.ac.uk. 
Lifestyle factors and small intestine adenocarcinoma risk: a systematic review and meta-analysis.

Short title: Small intestine cancer risk factors.

Authors: Caoimhe M Bennett ${ }^{1}$, Helen G Coleman ${ }^{1}$, Philip G Veal ${ }^{1,2}$, Marie M Cantwell ${ }^{1}$, Charlotte CL Lau ${ }^{1}$ and Liam J Murray ${ }^{1}$.

Affiliations of authors: ${ }^{1}$ Cancer Epidemiology \& Health Services Research Group, Centre for Public Health, Queens University Belfast, Northern Ireland. ${ }^{2}$ Public Health Agency, Northern Ireland

Corresponding author: Dr Helen Coleman. Centre for Public Health, Institute of Clinical Sciences, Block B, Queen's University Belfast, Royal Victoria Hospital, Grosvenor Road, Belfast, Northern Ireland, BT12 6BJ. E-mail: h.coleman@qub.ac.uk; Fax: (+44) 02890235900

Abbreviations: BMI: Body Mass Index, FFQ: Food Frequency Questionnaire, HRT: Hormone replacement therapy, SIA: Small Intestine Adenocarcinoma, HNPCC: Hereditary Nonpolyposis Colorectal Cancer. 


\section{Abstract}

Background: Although the incidence of small intestinal adenocarcinoma (SIA) is low, rates are increasing and little information regarding modifiable lifestyle risk factors is available.

Aim: To provide a systematic review of lifestyle factors and SIA risk.

Methods: Ovid MEDLINE, EMBASE and WEB OF SCIENCE were searched from inception to Week 1 October 2013. Nine publications that reported on SIA risk in relation to alcohol intake $(n=6)$, tobacco smoking $(n=6)$, diet $(n=5)$, body mass $(n=3)$, physical activity $(n=1)$, hormone use $(n=1)$ and/or socio-economic status $(n=3)$ were retrieved. Results for alcohol, smoking and SIA risk were pooled using random-effects meta-analyses to produce relative risks $(\mathrm{RR})$ and 95\% confidence intervals $(\mathrm{CI})$.

Results: The summary RR for individuals consuming the highest versus lowest category of alcohol intake was 1.51 (95\% CI $0.83-2.75 ; n=5$ studies $)$ with significant increased risks emerging in sensitivity analysis with reduced heterogeneity (RR: 1.82, 95\% CI: 1.05-3.15; $\mathrm{n}=4$ studies). The pooled SIA RR for individuals in the highest versus lowest category of smoking was $1.24(95 \%$ CI $0.71-2.17 ; \mathrm{n}=5$ studies $)$. In relation to dietary factors, high fibre intakes and normal body weight may be protective, while high intakes of red/processed meat and sugary drinks may increase SIA risk. Evidence on socio-economic status and SIA risk was equivocal. Data on other factors were too sparse to draw any conclusions.

Conclusions: Alcohol may be associated with an increased risk of SIA. Further investigation of lifestyle factors, particularly alcohol, smoking and diet, in the aetiology of this cancer is warranted in large consortial studies.

Keywords: small intestine; cancer; risk factors; diet; alcohol; smoking. 


\section{Introduction}

The small intestine represents $75 \%$ of the length and $90 \%$ of the absorptive surface of the gastrointestinal system [1]. Despite its prime role in digestion, the small intestine is a relatively rare location for the development of neoplasms, accounting for only $2 \%$ of all gastrointestinal cancers, $0.4 \%$ of total cancer cases and $0.2 \%$ of all cancer deaths [2]. Worryingly though, the incidence of small intestine cancer increased substantially between 1973 and 2004 [3], and others have noted that this trend disproportionately affects Caucasian men [4]. This nonuniform increase across population groups suggests that the rise is not due to improved classification of tumour location, generating a need to better understand the causative factors of this malignancy.

Amongst the different histological types of small intestine cancer, small intestine adenocarcinoma (SIA), derived from mucosal gland epithelium, is amongst the most common [5]. It accounts for $50 \%, 20 \%$ and $15 \%$ of duodenal, jejunal and ileal cancers, respectively [3]. Clinical manifestations of SIA are usually non-specific and appear late in the disease, presenting a challenge for physicians, since patients often present with advanced cancer [6,7]. This late presentation is coupled with a poor prognosis for SIA, which currently has an overall 5-year survival rate of approximately 30\% [8]. Therefore, in order to reduce future cancer burden, research emphasis must focus on preventative measures that may reduce SIA risk.

Certain medical conditions, including hereditary nonpolyposis colorectal cancer (HNPCC), Peutz-Jeghers syndrome and Crohn's Disease have been established as risk factors for SIA [6,9-14]. However, little is known about modifiable lifestyle factors that may be related to SIA, even though such factors are of considerable aetiological importance for other tumours of 
the gastrointestinal tract $[15,16]$. The purpose of this article is to conduct a novel systematic review, and meta-analyses where possible, evaluating the association between lifestyle factors and SIA development. 


\subsection{Search strategy}

The bibliographic databases Ovid MEDLINE (US National Library of Medicine, Bethesda, Maryland), EMBASE (Reed Elsevier PLC, Amsterdam, Netherlands) and Web of Science (Thompson Reuters, Times Square, New York, USA) were searched from inception to October week 12013 for literature related to lifestyle factors and SIA risk. The search strategy identified studies that contained at least one keyword or Medical Subject Heading (MeSH) term from each of the following:

(i) risk factor(s) OR alcohol drinking OR alcohol consumption OR diet OR nutrition OR smoking OR body mass index OR BMI OR occupation(s) OR socioeconomic status OR physical activity OR exercise OR radiation injuries OR radiation induced neoplasm(s) OR environmental exposure OR occupational exposure OR obesity OR medication OR hormone replacement therapy OR reproductive factors

AND

(ii) small intestine adenocarcinoma OR small bowel adenocarcinoma OR small intestine cancer OR small bowel cancer OR duodenal neoplasms OR ileal neoplasms OR jejunal neoplasms

The search strategy also incorporated limits to studies conducted on humans. Case studies, case series and review articles were removed, however no language restrictions were specified.

\subsection{Data extraction}

Titles and abstracts were independently examined by at least two reviewers (CB, HC, PV, MC, CL \&/or LM) to assess eligibility for the review using 'PICO' criteria:

(i) Participants: Males and females, no age restrictions 
(ii) Intervention: Assessment of lifestyle factors in the study population

(iii) Comparators: Healthy individuals with no small intestine cancer

(iv) Outcome: Small intestine adenocarcinoma risk

(v) Study design: Observational including cohort and case-control studies.

The reviewers initially screened titles and abstracts to remove obviously irrelevant articles, and then at least two reviewers (CB, BSc Hons, HC, PhD BSc Hons, and/or PV, MB BCh BSc MPH) screened full text articles independently to identify studies for inclusion in the systematic review. Discrepancies were resolved by discussion. Reference lists of included articles were also searched for other relevant studies. Since this systematic review focuses on SIA risk, studies were excluded if they presented data on small intestine cancer as one entity, or if they only presented data on small intestine sarcoma, small intestine lymphoma or small intestine neuroendocrine/carcinoid tumours. Studies that reported small intestine cancer as one entity were contacted to retrieve SIA specific data. Methodological quality was evaluated using the Newcastle-Ottawa Scale [17] to assess the selection of the study groups (zero to four points); the comparability of the groups (zero to two points); and the ascertainment of the exposure or outcome of interest (zero to three points).

\subsection{Narrative synthesis and statistical analysis}

Following critical review of each study, a narrative synthesis was compiled. Where possible, the association between cancer risk and lifestyle factors was summarised in meta-analyses by comparing risk in the highest to the lowest reported category of exposure. Adjusted relative risk estimates (RR) and their corresponding 95\% confidence intervals (CI) were extracted from published reports for each study. In case-control studies adjusted odds ratios (OR) were used, whereas adjusted hazard rate ratios (HR) were extracted from cohort studies, both of which 
should approximate RR since SIA is extremely rare [18]. Random-effects models were used to calculate pooled RR and the $\mathrm{I}^{2}$ statistic [19] was calculated to quantify the degree of heterogeneity between studies. Study specific weights in the random-effects model were calculated and scaled to percentages. An a priori decision was made to perform meta-analyses only for lifestyle risk factors that were investigated by at least 3 published studies. This meant that meta-analyses were possible for alcohol and smoking as risk factors for SIA. Publication and selection bias was investigated by checking for asymmetry in the funnel plots of the study RR against the standard error of the logarithm of the RR [20]. Sensitivity analyses were performed for alcohol and smoking meta-analyses by systematically removing each individual study in order to assess its effect on the pooled result estimates and accompanying heterogeneity. Statistical analysis was conducted using the metan package in Intercooled STATA version 11.2 (StataCorp 2005, College Station, TX, USA). 


\section{Results}

As shown in Figure 1, screening of the 2,319 papers identified in our search strategy resulted in nine publications [21-29] deemed eligible for inclusion in the review. The characteristics of these are summarised in Table 1 and consist of four studies from prospective cohorts or consortiums [21,23,24,28], two population-based case-control studies [25,29] and three hospital-based case-control studies [22,26,27]. These studies, of variable quality, originated from America, Europe and a large Asian cohort consortium (Table 1).

\subsection{Alcohol}

Four case-control studies and one cohort study examined alcohol consumption and SIA risk $[22,23,26,27,29]$. As shown in Figure 2, the pooled RR for those consuming the highest versus lowest category of alcohol intake was 1.51 (95\% CI: $0.83-2.75)$ with heterogeneity of $61.4 \%$. Sensitivity analysis significantly altered the results shown with the removal of the Negri et al study [27], making the pooled RR 1.82 (95\%CI: 1.05-3.15) and a reduced heterogeneity of $28.0 \%$ (Figure 3 ). Removal of other studies in sensitivity analysis did not markedly alter the results shown, or accompanying heterogeneity (Table 2). In addition, Kaerlev et al [26] investigated specific alcoholic drinks and observed significant increased risks of SIA for heavy consumers ( $\geq 25 \mathrm{~g}$ alcohol/day) of beer (OR 3.5; 95\% CI: $1.5-8.0)$ and spirits (OR $3.4 ; 95 \%$ CI: 1.3-9.2) but not wine. Contrastingly, no links between differing alcohol types and SIA risk was observed in an American case-control study [29].

\subsection{Smoking}

Four case-control studies and one prospective cohort study examined smoking and SIA risk and were able to be included in meta-analyses [22,23,26,27,29]. As shown in Figure 4, the pooled RR for those in the highest versus lowest category of smoking was 1.24 (95\% CI: 0.71 - 
2.17), with moderate evidence of heterogeneity (38.5\%). Sensitivity analysis excluding the results of individual study estimates did not significantly alter the results shown (Table 2). It should be noted that the measure of smoking exposure was relatively crude in some of the included studies, with few attempting to quantify smoking intensity or duration (Figure 4). Wu et al [29] did additionally report that the non-significant increased SIA risk remained for former smokers and by different strata of smoking intensity, duration or age of smoking initiation. One cohort consortium [21] also reported observing non-significant direct associations between smoking and overall small intestine cancer risk, which remained in analysis of SIA only. However, this study did not present RR and 95\% CI for SIA risk and therefore could not be incorporated in our meta-analysis.

\subsection{Diet}

Five studies assessed the relationship between various dietary factors and SIA risk [23,24,2729]. Three publications $[23,24,28]$ originated from the large American National Institutes of Health-AARP Diet and Health Study. After adjustment for potential confounders outlined in Table 1, non-significant direct associations were observed between SIA risk and fat, processed and red meat intake [24] in that cohort. The latter finding was stronger in an Italian casecontrol study [27], which reported a significant increased SIA risk in subjects consuming more than five portions of red meat per week (OR 4.57; 95\% CI: 1.01-20.81). The most recent NIHAARP study investigated multivitamin use but did not find any significant associations with SIA risk (HR; 1.34 95\% CI: 0.70-2.57) (23). Furthermore, another case-control study [29] described an increased SIA risk for males who regularly ate foods high in heterocyclic aromatic amines (fried bacon/ham, barbecued and smoked meats, fish); no similar associations were found for female subjects, or for all subjects combined. 
Various aspects of carbohydrate intake have also been investigated in relation to SIA risk in these studies. Non-significant inverse associations were identified for fibre and wholegrain intake and SIA development in the American cohort study [28]. Alternatively, the American case-control study determined that SIA risk was heightened by the practice of adding sugar to either coffee or tea (OR 2.5; 95\% CI: 1.2-5.4) and by daily consumption of sugar-sweetened carbonated soft drinks (OR 3.6; 95\% CI: 1.3-9.8) in both males and females [29]. An Italian case-control study [27] also reported significant direct association between sugar, bread, pasta and rice intake and SIA risk. The same study reported potentially protective effects against SIA development for individuals consuming the highest weekly intake of vegetables (OR 0.27; 95\% CI: 0.09-0.85) and, to a lesser extent, coffee.

\subsection{Body fatness}

Three studies assessed BMI as an exposure for SIA risk [21,23,27]. One case-control study has explored body fatness and SIA development, in which risk was significantly elevated for underweight individuals [27]. There may be a U-shaped relationship for body fatness and SIA risk, since the Asian cohort consortium [21] reported significantly elevated risks for overweight individuals also (RR 1.89; 95\% CI: 0.63-5.68). Finally, the highest increased risk in the NIHAARP cohort [23] was in the severely obese (BMI $>35 \mathrm{~kg} / \mathrm{m}^{2}$ ) category (HR: $1.3595 \% \mathrm{CI}$ : 0.56-3.28), however this was not statistically significant.

\subsection{Socio-economic status}

The relationship between SIA risk and socio-economic factors, reflected by either education $[23,27]$ or occupation [25], has been explored in three studies. No significant associations were observed between education and SIA carcinogenesis [23,27], whereas several occupations 
were found to carry significant elevated SIA risks in a European study [25]. This included men employed as building caretakers and welders, and women employed as housekeepers, general farm labourers, dockers, dry cleaners or launderers, and textile workers [25]. Moreover, direct dose-response relationships were noted for duration of employment and SIA risk in many of these occupations [25].

\subsection{Other Factors}

One cohort study investigated self-reported physical activity and SIA risk [23]. A nonsignificant association was identified for SIA risk in individuals self-reporting that they undertook vigorous physical activity $\geq 5$ times/week compared with those undertaking no vigorous physical activity (HR: 0.67; 95\% CI: 0.33-1.34).

The same cohort study [23] also investigated menopausal hormone therapy use and SIA risk and noted a decreased risk of SIA in current HRT users (HR: $0.51 ; 95 \%$ CI: 0.21-1.24), and an even greater decreased risk in former HRT users (HR: 0.51; 95\% CI: 0.04-2.40), compared with never HRT users. However neither of these results achieved statistical significance. 


\section{Discussion}

Nine observational studies investigated a range of modifiable lifestyle factors and SIA risk. Meta-analyses suggested that alcohol consumption may increase the risk of SIA and tobacco smoking may be associated with a non-significant increased SIA risk. Limited data suggested that consumption of excess meat and sugary drinks may have an aetiological role for this cancer, while both low and high body fatness were linked with SIA risk. The association between socio-economic status, other lifestyle factors and SIA development remains uncertain.

Pooled analysis of the five studies that reported on alcohol intake did not give a significant association, however sensitivity analysis with reduced heterogeneity and the removal of the Negri study showed a significant $82 \%$ increased risk of SIA in the highest category of alcohol consumption versus the lowest consumption category. The Negri et al study [27] was an Italianbased case-control study and may have differed from other studies due to its lower quality scale score or the classification of alcohol intake used (with the lowest category as $\leq 2$ drinks/day and highest category as $>2$ drinks/day). Interestingly, one European study implicated specific alcohol types such as beer and spirits as having an aetiological role in SIA development [26], however this was not replicated in an American study [29]. These differing results may be due to the difference in approach to collecting data on alcohol use between the studies and further work is required to explore this suggestion.

Alcohol has previously been associated with cancers of the head and neck, oesophagus, breast, liver and colorectum [16]. It is suggested that acetaldehyde, the genotoxic primary metabolite formed by the breakdown of ethanol may be carcinogenic [21,30]. Evidence further suggests that reduced folate levels and inhibition of key enzymes in one-carbon metabolism from alcohol consumption lead to altered patterns of DNA methylation, the mechanism of 
translational control, to influence cancer growth [31]. There is some evidence to suggest that ethanol may also act as an irritant to the small intestine mucosa, disrupting the mucosal barrier and therefore increasing susceptibility to other carcinogens [32].

Pooled analysis of data from the five studies that reported on tobacco use showed no significant increase in SIA risk for smokers. Smoking and exposure to tobacco have been cited as the leading single avoidable cause of cancer [16,33]. Possible carcinogenic mechanisms operating in the small intestine include the deposition of tobacco-specific nitrosamines via the circulatory system, impaired induction of enzyme systems that detoxify polycylic aromatic hydrocarbons and a reduced cellular response to immune challenge [33].

Five studies within the systematic review identified a breadth of dietary exposures and SIA risk. Publications arising from a well-conducted cohort study [23,24,28] observed a nonsignificant trend for reduction in risk of SIA with fibre and wholegrain intake and only weak direct associations with fat or meat intake. A number of epidemiological studies have found dietary fibre, and more recently whole grains, to be inversely associated with colorectal cancer [34]. It has therefore been hypothesised that protective associations in the large intestine may also exist in the small intestine. Fibre and whole grain are involved in bile acid and carcinogen binding, and decrease transit time in the small intestine, resulting in less contact time between potential carcinogens and the mucosa surface [35]. These biologically plausible mechanisms and suggestion of a protective effect warrant further investigation in future studies.

The potential for an increased risk of SIA with high red meat intake is not surprising, as red meat is a source of several known mutagenic mutagens, including heterocyclic amines [36], polycyclic aromatic hydrocarbons [37], and $N$-nitroso compounds [38]. These mutagens have 
been associated with other gastrointestinal cancers, including colorectal and oesophageal cancers $[39,40]$. Increased SIA risks were reported by the two case-control studies reviewed [27,29], but were not statistically significant in a cohort investigation [24]. The discrepancy between these study designs may be due to recall bias and differences in the dietary assessment tool utilised. Other evidence from the case-control studies suggest vegetables may have a protective effect on SIA risk [27], while the use of sugar in tea and coffee and consumption of carbonated soft drinks may increase SIA risk [29]. Clinical experimental data exists to suggest a biological basis for both observations [41], however this area requires more research.

Three published studies have considered the relationship between BMI and SIA [21,23,27], one of which found a tendency towards increased risk for underweight individuals [27], while the others found increased SIA risks for overweight/obese individuals [21,23]. The existence of a U-shaped association between body fatness and cancer risk has been demonstrated for other cancer sites, particularly for smoking-related malignancies $[16,42,43]$. This may reflect malnourishment associated with limited calorie intake that would arise in low body fatness [16], while excess body fat has a number of detrimental health effects, such as insulin resistance, that may lead to cancer development [44], in addition to reflecting a sedentary lifestyle. Only one study investigated physical activity and observed a non-significant decrease in SIA risk with increasing hours of physical activity. Physical activity may decrease SIA risk due to increased insulin sensitivity, weight maintenance, and transient systemic acidosis, which may delay cancer progression [45]. Further research is warranted, although measurement of physical activity in large cohort studies is difficult.

A number of occupations were associated with an increased risk in a European study, namely dry cleaners, textile workers and welders [25]. Workers in these occupations may have been 
exposed to chemical agents, such as perchlorethylene, which have been associated with other cancer aetiology [46]. Further studies focusing on specific exposures in these occupations would help to characterise these further, and possibly identify common exposures among cases of SIA. Limited evidence would suggest these findings are not a proxy for socio-economic status, since no significant associations were identified in one study that assessed educational status and SIA risk [25]. One study investigated HRT as a lifestyle risk factor and no significant results were observed [23]. The associations identified in this study should be regarded as exploratory, and require further investigation.

The magnitude of the observed associations for lifestyle factors, however, is relatively small compared with those known for the established non-modifiable risk factors of SIA. Namely, HNPCC, which is caused by a germline mutation of a DNA mismatch repair gene [14], and carries a varying risk of developing SIA depending on mutations and stage of syndrome. The relative risk estimate of SIA for MLH1 mutation ranges from 25 to 291 [47], and 103 for MSH2 mutation [48]. However lifetime cumulative risk of SIA is low, between $0.6 \%$ and $1 \%[9,13]$. Further, patients with Crohn's disease or Peutz-Jeghers syndrome carry 12-fold and 52-fold increased risks of SIA, respectively $[11,49]$. Although the increased risk of SIA with lifestyle risk factors is much lower than the aforementioned risk factors, the results are still of importance due to the increasing incidence of the disease and potential to modify this.

This systematic review has some limitations. Several studies were excluded that studied the relationship between lifestyle risk factors and small intestine cancer as a single entity. These were discarded because the histological types differ significantly in their biology, and different risk factors may be operating in each. This review focussed on SIA for several reasons: it is the most common histological subtype, the incidence is rising, clinical diagnosis is difficult, 
and 5-year survival is poor $[3,8]$. Whilst we had to exclude studies that evaluated risk of small intestinal cancer overall, these generally found associations for lifestyle factors, in line with the findings in the current review [50-55]. The majority of published work has been of a casecontrol nature, mainly due to the rarity of the disease. Opportunities to improve study quality could be achieved through improved measurement of exposures or by establishing consortial studies, such as the included Asian Cohort Consortium [21] to provide information on a larger number of cases through pooling of data. Aside from this consortium, the remaining studies largely reflect Western populations, meaning that our conclusions have poor generalisability to other population groups. However, a major strength of this review is the inclusion of novel meta-analyses of smoking and alcohol in relation to SIA risk, which may guide future research directions in this area.

In conclusion, high alcohol intake may be associated with an increased risk of SIA, and smoking may be associated with a non-significant increased risk. Red/processed meat and sugary drinks may be positively associated and fibre intake and normal body weight inversely associated with risk of SIA. However, these links require further investigation. Due to the low incidence of SIA, further case-control studies or large cohort studies would be welcome to address the paucity of evidence in this area. 


\section{References}

[1] Schottenfeld D, Beebe-Dimmer JL, Vigneau FD. The Epidemiology and Pathogenesis of Neoplasia in the Small Intestine. Ann Epidemiol 2009;19(1):58-69.

[2] Jemal A, Siegel R, Ward E, Hao Y, Xu J, Murray T, et al. Cancer statistics, 2008. CA Cancer J Clin 2008;58(2):71-96.

[3] Gustafsson BI, Siddique L, Chan A, Dong M, Drozdov I, Kidd M, et al. Uncommon cancers of the small intestine, appendix and colon: an analysis of SEER 1973-2004, and current diagnosis and therapy. Int J Oncol 2008;33(6):1121-1131.

[4] Chow JS, Chen CC, Ahsan H, Neugut AI. A population-based study of the incidence of malignant small bowel tumours: SEER, 1973-1990. Int J Epidemiol 1996;25(4):722-728.

[5] Haselkorn T, Whittemore A, Lilienfeld D. Incidence of small bowel cancer in the United States and worldwide: geographic, temporal, and racial differences. Cancer Causes Control 2005;16(7):781-787.

[6] Delaunoit T, Neczyporenko F, Limburg PJ, Erlichman C. Pathogenesis and risk factors of small bowel adenocarcinoma: A colorectal cancer sibling?. Am J Gastroenterol 2005;100(3):703-710.

[7] Raghav K, Overman MJ. Small bowel adenocarcinomas--existing evidence and evolving paradigms. Nat Rev Clin Oncol 2013;10(9):534-544.

[8] Bilimoria KY, Bentrem DJ, Wayne JD, Ko CY, Bennett CL, Talamonti MS. Small bowel cancer in the United States: changes in epidemiology, treatment, and survival over the last 20 years. Ann Surg 2009;249(1):63-71. 
[9] Aarnio M, Mecklin JP, Aaltonen LA, Nystrom-Lahti M, Jarvinen HJ. Life-time risk of different cancers in hereditary non-polyposis colorectal cancer (HNPCC) syndrome. Int $J$ Cancer 1995;64(6):430-433.

[10] Canavan C, Abrams KR, Mayberry J. Meta-analysis: colorectal and small bowel cancer risk in patients with Crohn's disease. Aliment Pharmacol Ther 2006;23(8):1097-1104.

[11] Giardiello FM, Brensinger JD, Tersmette AC, Goodman SN, Petersen GM, Booker SV, et al. Very high risk of cancer in familial Peutz-Jeghers syndrome. Gastroenterology 2000;119(6):1447-1453.

[12] Jess T, Winther KV, Munkholm P, Langholz E, Binder V. Intestinal and extra-intestinal cancer in Crohn's disease: follow-up of a population-based cohort in Copenhagen County, Denmark. Aliment Pharmacol Ther 2004;19(3):287-293.

[13] Bonadona V, Bonaiti B, Olschwang S, Grandjouan S, Huiart L, Longy M, et al. Cancer risks associated with germline mutations in MLH1, MSH2, and MSH6 genes in Lynch syndrome. JAMA 2011;305(22):2304-2310.

[14] Aparicio T, Zaanan A, Svrcek M, Laurent-Puig P, Carrere N, Manfredi S, et al. Small bowel adenocarcinoma: epidemiology, risk factors, diagnosis and treatment. Dig Liver Dis 2014;46(2):97-104.

[15] Huxley R, Ansary-Moghaddam A, Berrington de Gonzalez A, Barzi F, Woodward M. Type-II diabetes and pancreatic cancer: a meta-analysis of 36 studies. Br J Cancer 2005;92(11):2076-2083. 
[16] World Cancer Research Fund/American Institute for Cancer Research. Food, Nutrition, Physical Activity, and the Prevention of Cancer: a Global Perspective. 2007. Washington DC: AICR.

[17] Wells GA, Shea B, O'Connell D, Peterson J, Welch V, Losos M, et al. The NewcastleOttawa Scale (NOS) for assessing the quality of nonrandomized studies in meta-analyses. Available at: http://www.lri.ca/programs/ceu/oxford.htm. Accessed Nov, 2007.

[18] Symons MJ, Moore DT. Hazard rate ratio and prospective epidemiological studies. J Clin Epidemiol 2002;55(9):893-899.

[19] Higgins JP, Thompson SG, Deeks JJ, Altman DG. Measuring inconsistency in metaanalyses. BMJ 2003;327(7414):557-560.

[20] Sterne JA, Egger M. Funnel plots for detecting bias in meta-analysis: guidelines on choice of axis. J Clin Epidemiol 2001;54(10):1046-1055.

[21] Boffetta P, Hazelton WD, Chen Y, Sinha R, Inoue M, Gao YT, et al. Body mass, tobacco smoking, alcohol drinking and risk of cancer of the small intestine-a pooled analysis of over 500000 subjects in the Asia Cohort Consortium. Ann Oncol 2012;23(7)1894-1898.

[22] Chen CC, Neugut AI, Rotterdam H. Risk factors for adenocarcinomas and malignant carcinoids of the small intestine: Preliminary findings. Cancer Epidemiol Biomarkers Prev 1994;3(3):205-207.

[23] Cross AJ, Hollenbeck AR, Park Y. A large prospective study of risk factors for adenocarcinomas and malignant carcinoid tumors of the small intestine. Cancer Causes Control 2013;24(9):1737-1746. 
[24] Cross AJ, Leitzmann MF, Subar AF, Thompson FE, Hollenbeck AR, Schatzkin A. A prospective study of meat and fat intake in relation to small intestinal cancer. Cancer Res 2008;68(22):9274-9279.

[25] Kaerlev L, Teglbjaerg PS, Sabroe S, Kolstad HA, Ahrens W, Eriksson M, et al. Occupation and small bowel adenocarcinoma: A European case-control study. Occup Environ Med 2000;57(11):760-766.

[26] Kaerlev L, Teglbjaerg PS, Sabroe S, Kolstad HA, Ahrens W, Eriksson M, et al. Is there an association between alcohol intake or smoking and small bowel adenocarcinoma? Results from a European multi-center case-control study. Cancer Causes Control 2000;11(9):791797.

[27] Negri E, Bosetti C, La Vecchia C, Fioretti F, Conti E, Franceschi S. Risk factors for adenocarcinoma of the small intestine. Int J Cancer 1999;82(2):171-174.

[28] Schatzkin A, Park Y, Leitzmann MF, Hollenbeck AR, Cross AJ. Prospective study of dietary fiber, whole grain foods, and small intestinal cancer. Gastroenterology 2008;135(4):1163-1167.

[29] Wu A, Yu M, Mack T. Smoking, alcohol use, dietary factors and risk of small intestinal adenocarcinoma. Int J Cancer 1997;70(5):512-517.

[30] Boffetta P, Hashibe M. Alcohol and cancer. Lancet Oncol 2006;7(2):149-156.

[31] Varela-Rey M, Woodhoo A, Martinez-Chantar ML, Mato JM, Lu SC. Alcohol, DNA methylation, and cancer. Alcohol Res 2013;35(1):25-35. 
[32] Burbige EJ, Lewis DR,Jr, Halsted CH. Alcohol and the gastrointestinal tract. Med Clin North Am 1984;68(1):77-89.

[33] World Health Organisation/International Association for Research on Cancer. Tobacco Smoke and Involuntary Smoking, IARC Monographs Volume 83. 2004.

[34] Aune D, Chan DS, Lau R, Vieira R, Greenwood DC, Kampman E, et al. Dietary fibre, whole grains, and risk of colorectal cancer: systematic review and dose-response metaanalysis of prospective studies. BMJ 2011;343:d6617.

[35] Slavin JL. Mechanisms for the impact of whole grain foods on cancer risk. J Am Coll Nutr 2000;19(3 Suppl):300S-307S.

[36] Sinha R, Kulldorff M, Chow WH, Denobile J, Rothman N. Dietary intake of heterocyclic amines, meat-derived mutagenic activity, and risk of colorectal adenomas. Cancer Epidemiol Biomarkers Prev 2001;10(5):559-562.

[37] Sinha R, Kulldorff M, Gunter MJ, Strickland P, Rothman N. Dietary benzo[a]pyrene intake and risk of colorectal adenoma. Cancer Epidemiol Biomarkers Prev 2005;14(8):20302034.

[38] Hughes R, Cross AJ, Pollock JR, Bingham S. Dose-dependent effect of dietary meat on endogenous colonic N-nitrosation. Carcinogenesis 2001;22(1):199-202.

[39] Knekt P, Jarvinen R, Dich J, Hakulinen T. Risk of colorectal and other gastro-intestinal cancers after exposure to nitrate, nitrite and N-nitroso compounds: a follow-up study. Int $J$ Cancer 1999;80(6):852-856. 
[40] Rogers MA, Vaughan TL, Davis S, Thomas DB. Consumption of nitrate, nitrite, and nitrosodimethylamine and the risk of upper aerodigestive tract cancer. Cancer Epidemiol Biomarkers Prev 1995;4(1):29-36.

[41] La Vecchia C. Mediterranean diet and cancer. Public Health Nutr 2004;7(7):965-968.

[42] Franceschi S, Dal Maso L, Levi F, Conti E, Talamini R, La Vecchia C. Leanness as early marker of cancer of the oral cavity and pharynx. Ann Oncol 2001;12(3):331-336.

[43] Renehan AG, Tyson M, Egger M, Heller RF, Zwahlen M. Body-mass index and incidence of cancer: a systematic review and meta-analysis of prospective observational studies. Lancet 2008;371(9612):569-578.

[44] Giovannucci E, Michaud D. The role of obesity and related metabolic disturbances in cancers of the colon, prostate, and pancreas. Gastroenterology 2007;132(6):2208-2225.

[45] Smallbone K, Maini PK, Gatenby RA. Episodic, transient systemic acidosis delays evolution of the malignant phenotype: Possible mechanism for cancer prevention by increased physical activity. Biol Direct 2010;5:22-6150-5-22.

[46] Weiss NS. Cancer in relation to occupational exposure to perchloroethylene. Cancer Causes Control 1995;6(3):257-266.

[47] Watson P, Lynch HT. Extracolonic cancer in hereditary nonpolyposis colorectal cancer. Cancer 1993;71(3):677-685.

[48] Vasen HF, Wijnen JT, Menko FH, Kleibeuker JH, Taal BG, Griffioen G, et al. Cancer risk in families with hereditary nonpolyposis colorectal cancer diagnosed by mutation analysis. Gastroenterology 1996;110(4):1020-1027. 
[49] Shaukat A, Virnig DJ, Howard D, Sitaraman SV, Liff JM, Lederle FA. Crohn's disease and small bowel adenocarcinoma: a population-based case-control study. Cancer Epidemiol Biomarkers Prev 2011;20(6):1120-1123.

[50] Chow W, Linet MS, McLaughlin JK, Hsing AW, Co Chien HT, Blot WJ. Risk factors for small intestine cancer. Cancer Causes Control 1993;4(2):163-169.

[51] Sorahan T. Cancer incidence in UK electricity generation and transmission workers, 1973-2008. Occup Med 2012;62(7):496-505.

[52] Verma D, Stroehlein JR. Adenocarcinoma of the small bowel: A 60-yr perspective derived from M. D. Anderson Cancer Center Tumor Registry. Am J Gastroenterol 2006;101(7):1647-1654.

[53] Tasevska N, Jiao L, Cross AJ, Kipnis V, Subar AF, Hollenbeck A, et al. Sugars in diet and risk of cancer in the NIH-AARP Diet and Health Study. Int J Cancer 2012;130(1):159169.

[54] Hatzaras I, Palesty JA, Abir F, Sullivan P, Kozol RA, Dudrick SJ, et al. Small-bowel tumors - Epidemiologic and clinical characteristics of 1260 cases from the Connecticut Tumor Registry. Arch Surg 2007;142(3):229-235.

[55] Bjorge T, Tretli S, Engeland A. Height and body mass index in relation to cancer of the small intestine in two million Norwegian men and women. Br J Cancer 2005;93(7):807-810. 


\section{Financial support}

The authors of this paper are employees and current/former students of Queen's University Belfast and have received funding from Cancer Research UK and the UKCRC Centre of Excellence for Public Health Northern Ireland.

\section{Authorship statement}

Guarantor of the article: HG Coleman.

Specific author contributions: LJ Murray had the review concept; CM Bennett, PG Veal, HG Coleman, LJ Murray, and MM Cantwell developed the search strategy; CM Bennett, PG Veal, LJ Murray, MM Cantwell, HG Coleman and CC Lau conducted study selection; CM Bennett, PG Veal and HG Coleman conducted the search strategy, data extraction, metaanalyses and wrote the first draft of the manuscript; All authors contributed to the editing and approval of the final draft of the manuscript. 
Table 1: Characteristics of studies of risk factors of small intestine adenocarcinoma.

\begin{tabular}{|c|c|c|c|c|c|c|c|c|c|c|c|c|c|c|c|c|c|}
\hline \multirow[t]{2}{*}{ Study-year-location } & \multirow[t]{2}{*}{ Study design } & \multirow[t]{2}{*}{ Cases } & \multirow{2}{*}{$\begin{array}{l}\text { Controls/ } \\
\text { Cohort } \\
\text { size }\end{array}$} & \multirow{2}{*}{$\begin{array}{l}\text { Assessment } \\
\text { tool }\end{array}$} & \multirow{2}{*}{$\begin{array}{l}\text { NO } \\
\text { scale } \\
\text { score }\end{array}$} & \multirow{2}{*}{$\begin{array}{l}\text { Exposures } \\
\text { measured }\end{array}$} & \multicolumn{11}{|c|}{ Adjusted confounders } \\
\hline & & & & & & & $\stackrel{8}{<}$ & & $\begin{array}{l} \\
\frac{0}{2} \\
0 \\
0 \\
\end{array}$ & 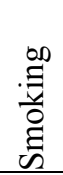 & .0 & 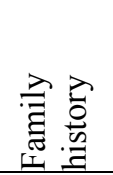 & $\sum_{\infty}$ & 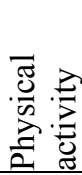 & 荘 & $\stackrel{. \oplus}{E}$ & 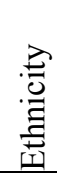 \\
\hline $\begin{array}{l}\text { Cross et al. 2013, } \\
\text { USA [23] }\end{array}$ & $\begin{array}{l}\text { Prospective } \\
\text { cohort }\end{array}$ & 84 & 498,376 & $\begin{array}{l}\text { Self-reported } \\
\text { 124-item FFQ }\end{array}$ & 9 & $\begin{array}{l}\text { BMI, } \\
\text { Smoking } \\
\text { Alcohol } \\
\text { Education } \\
\text { Multivitamins, } \\
\text { Physical activity } \\
\text { HRT }\end{array}$ & $\checkmark$ & $\checkmark$ & & & & & & & & & \\
\hline $\begin{array}{l}\text { Boffetta et al. 2011, } \\
\text { Asia [21] }\end{array}$ & $\begin{array}{l}\text { Prospective } \\
\text { cohort }\end{array}$ & 49 & 527,592 & Questionnaire & 9 & $\begin{array}{l}\text { BMI } \\
\text { Smoking* } \\
\text { Alcohol* }\end{array}$ & $\checkmark$ & $\checkmark \checkmark$ & & & $\checkmark$ & & $\checkmark$ & & & & \\
\hline $\begin{array}{l}\text { Schatzkin et al. 2008, } \\
\text { USA [28] }\end{array}$ & $\begin{array}{l}\text { Prospective } \\
\text { cohort }\end{array}$ & 60 & 492,321 & $\begin{array}{l}\text { Self-reported } \\
\text { 124-item FFQ }\end{array}$ & 9 & $\begin{array}{l}\text { Diet: fibre, } \\
\text { wholegrains }\end{array}$ & $\checkmark$ & $\checkmark$ & & $\checkmark$ & $\checkmark$ & $\checkmark$ & & & $\checkmark$ & $\checkmark$ & \\
\hline $\begin{array}{l}\text { Cross et al. 2008, } \\
\text { USA [24] }\end{array}$ & $\begin{array}{l}\text { Prospective } \\
\text { cohort }\end{array}$ & 60 & 494,000 & $\begin{array}{l}\text { Self-reported } \\
124 \text {-item FFQ }\end{array}$ & 9 & Diet: meats, fats & $\checkmark$ & $\checkmark \checkmark$ & & $\checkmark$ & $\checkmark$ & $\checkmark$ & $\checkmark$ & & $\checkmark$ & $\checkmark$ & \\
\hline $\begin{array}{l}\text { Kaerlev et al. 2000, } \\
\text { Denmark [25] }\end{array}$ & $\begin{array}{l}\text { Population based } \\
\text { case-control }\end{array}$ & 79 & 2649 & Questionnaire & 7 & Occupation & $\checkmark$ & $\checkmark$ & & & & & & & & & $\checkmark$ \\
\hline $\begin{array}{l}\text { Kaerlev et al. 2000, } \\
\text { Denmark [26] }\end{array}$ & $\begin{array}{l}\text { Hospital based } \\
\text { case-control }\end{array}$ & 70 & 2070 & Questionnaire & 9 & $\begin{array}{l}\text { Smoking } \\
\text { Alcohol }\end{array}$ & $\checkmark$ & $\checkmark$ & & & $\checkmark$ & & & & & & $\checkmark$ \\
\hline $\begin{array}{l}\text { Negri et al. 1999, } \\
\text { Italy [27] }\end{array}$ & $\begin{array}{l}\text { Hospital based } \\
\text { case-control }\end{array}$ & 23 & 230 & Questionnaire & 6 & $\begin{array}{l}\text { BMI } \\
\text { Smoking } \\
\text { Alcohol } \\
\text { Diet: multiple factors } \\
\text { Education }\end{array}$ & $\checkmark$ & $\checkmark$ & & & & & $\checkmark$ & & & & \\
\hline $\begin{array}{l}\text { Wu et al. 1997, } \\
\text { USA [29] }\end{array}$ & $\begin{array}{l}\text { Population based } \\
\text { case- control }\end{array}$ & 36 & 998 & Questionnaire & 8 & $\begin{array}{l}\text { Smoking } \\
\text { Alcohol } \\
\text { Diet: multiple factors }\end{array}$ & $\checkmark$ & $\checkmark$ & & & & & & & & & $\checkmark$ \\
\hline $\begin{array}{l}\text { Chen et al. 1994, } \\
\text { USA [22] }\end{array}$ & $\begin{array}{l}\text { Hospital based } \\
\text { case- control }\end{array}$ & 19 & 52 & $\begin{array}{l}\text { Medical records } \\
\text { reviewed }\end{array}$ & 6 & $\begin{array}{l}\text { Smoking } \\
\text { Alcohol }\end{array}$ & $\checkmark$ & $\checkmark \checkmark$ & & $\checkmark$ & & & & & & & \\
\hline
\end{tabular}

*Separate RR and 95\% CI were not presented for smoking or alcohol use and SIA risk by Boffetta et al, therefore did not contribute to meta-analyses but are discussed in results text.

NO scale score: Newcastle-Ottawa quality scale score (maximum score of 9).

Adjusted confounders: Age; Sex; Follow-up time; Education; Family history of cancer, BMI: Body Mass Index; Physical activity; HRT: Hormone Replacement Therapy;

Diet: Aspects of diet assessed as confounders were varied; Ethnicity: Ethnicity, race or country of origin. 
Table 2. Sensitivity analysis excluding individual studies from meta-analysis.

\begin{tabular}{|llll|}
\hline & $\begin{array}{l}\text { Pooled risk estimate } \\
(95 \% \text { CI })\end{array}$ & $\begin{array}{l}\text { I-squared } \\
(\%)\end{array}$ & p-value \\
\hline Smoking & & & \\
\hline Excluding Chen et al [22] & $1.12(0.70-1.79)$ & $14.4 \%$ & 0.64 \\
Excluding Cross et al [23] & $1.37(0.72-2.61)$ & $46.7 \%$ & 0.34 \\
Excluding Kaerlev et al [26] & $1.15(0.52-2.56)$ & $50.1 \%$ & 0.72 \\
Excluding Negri et al [27] & $1.48(0.91-2.42)$ & $13.1 \%$ & 0.12 \\
Excluding Wu et al [29] & $1.20(0.56-2.58)$ & $53.4 \%$ & 0.65 \\
\hline Alcohol & & & \\
\hline Excluding Chen et al [22] & $1.31(0.72-2.37)$ & $46.0 \%$ & 0.38 \\
Excluding Cross et al [23] & $1.49(0.71-3.17)$ & $61.4 \%$ & 0.30 \\
Excluding Kaerlev et al [26] & $1.72(0.77-3.87)$ & $57.2 \%$ & 0.19 \\
Excluding Negri et al [27] & $1.82(1.05-3.15)$ & $28.0 \%$ & 0.03 \\
Excluding Wu et al [29] & $1.28(0.67-2.47)$ & $45.2 \%$ & 0.46 \\
\hline
\end{tabular}


Figure1. Flow diagram of study selection.

Potentially relevant papers identified through search of $\operatorname{MEDLINE}(\mathrm{n}=344)$
Potentially relevant papers identified through search of $\operatorname{EMBASE}(n=415)$
Potentially relevant papers identified through search of WEB

OF SCIENCE $(n=1950)$

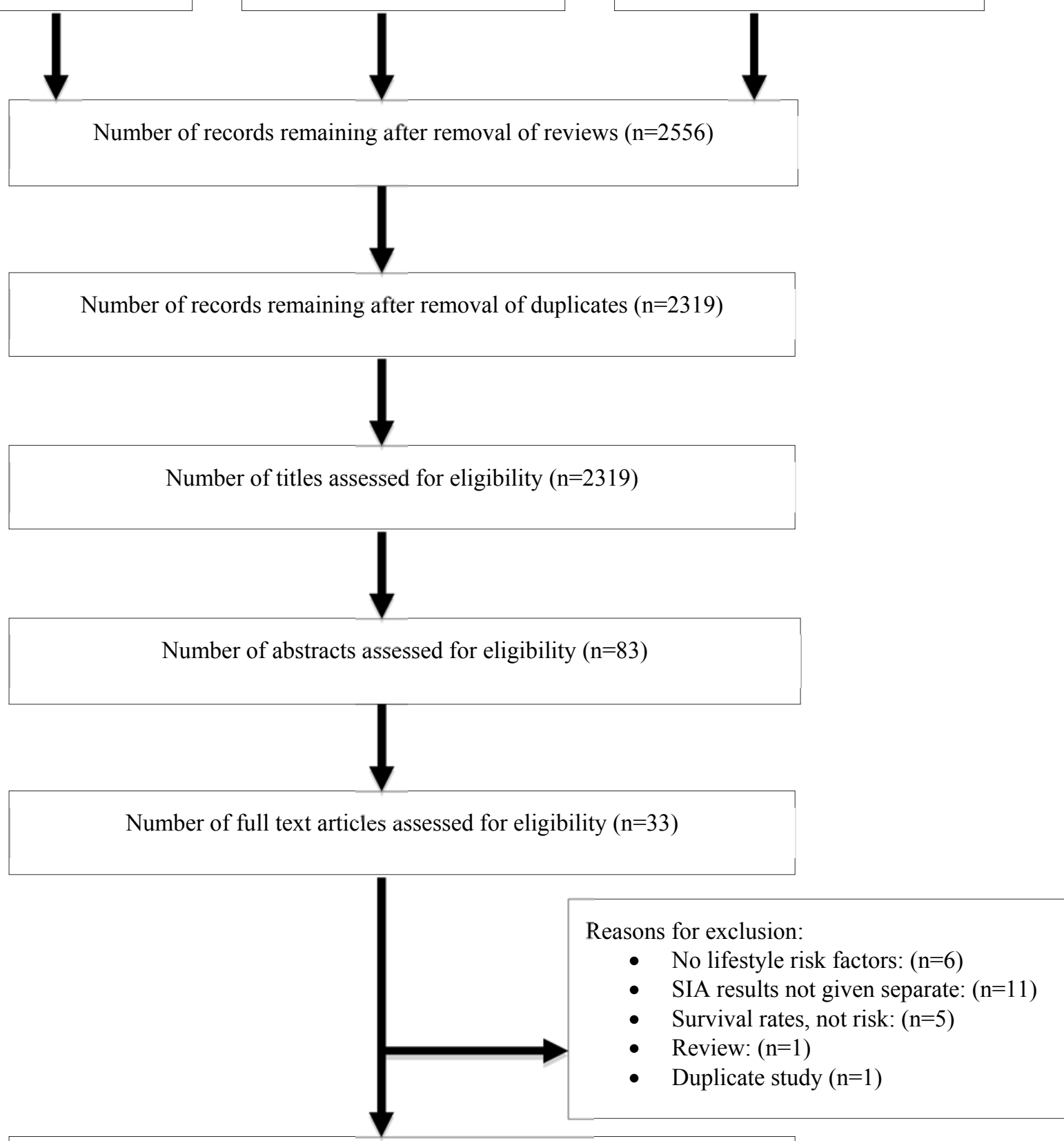

Number of articles included in systematic review after application of exclusion criteria $(n=9)$ 
Figure 2. Forest plot of highest versus lowest category of alcohol intake and small intestine adenocarcinoma risk

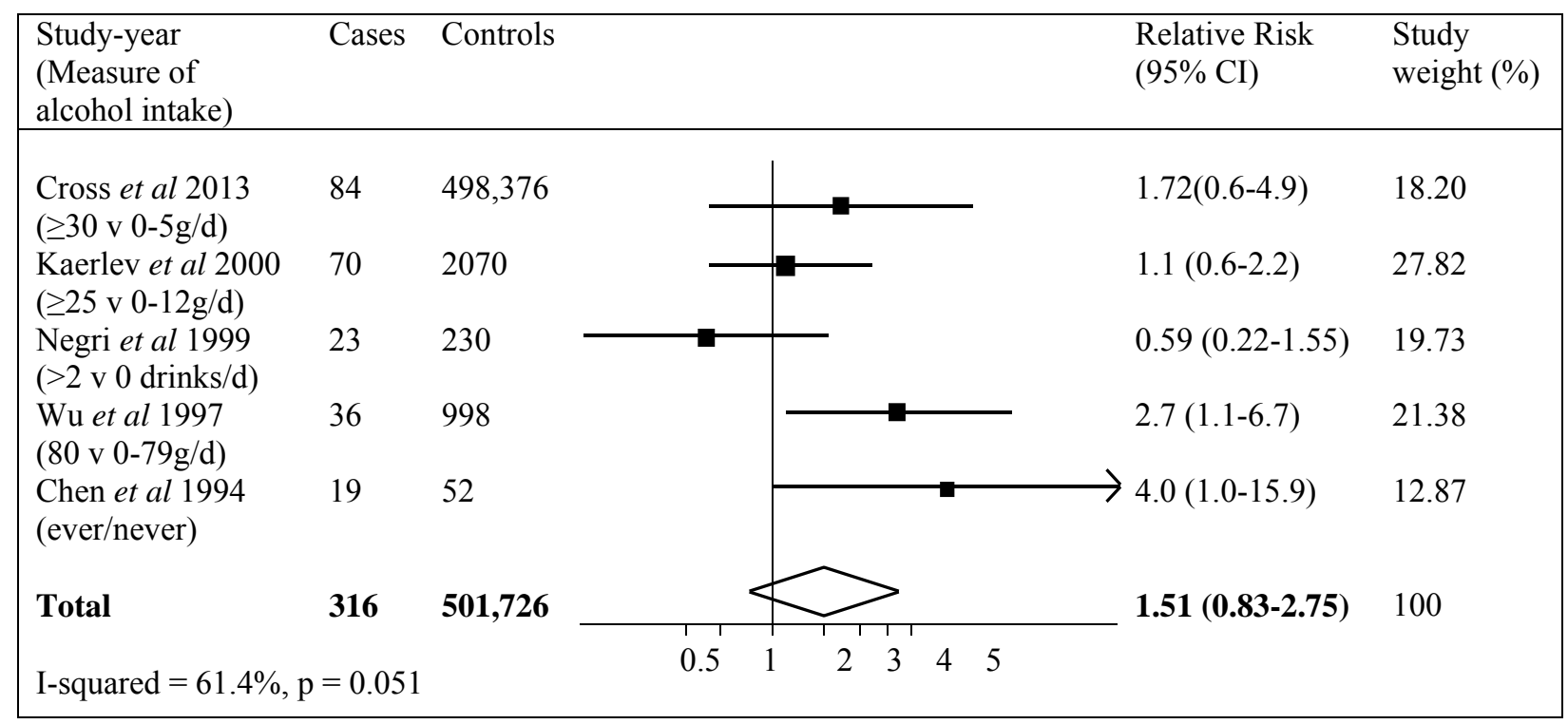


Figure 3. Forest plot of highest versus lowest category of alcohol intake and small intestine adenocarcinoma risk (excluding Negri et al).

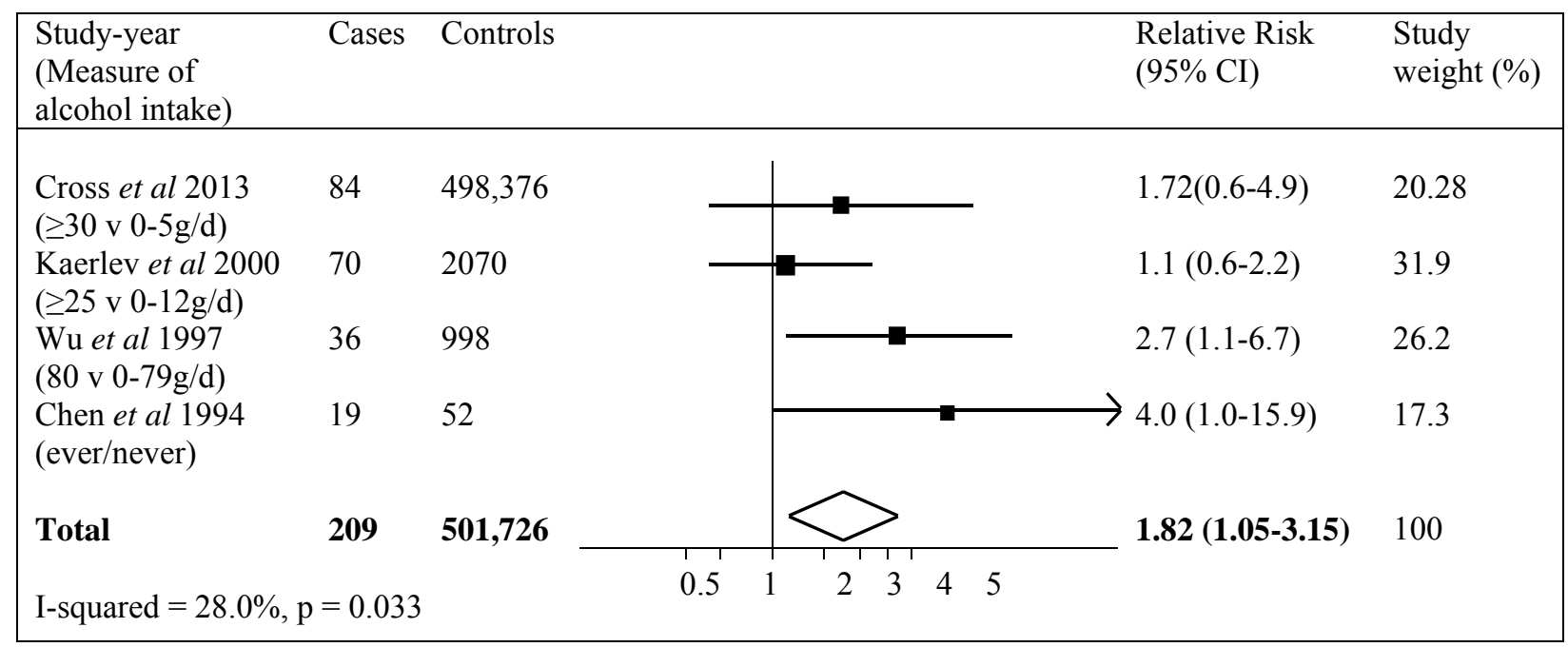


Figure 4. Forest plot of highest versus lowest category of smoking and small intestine adenocarcinoma risk.

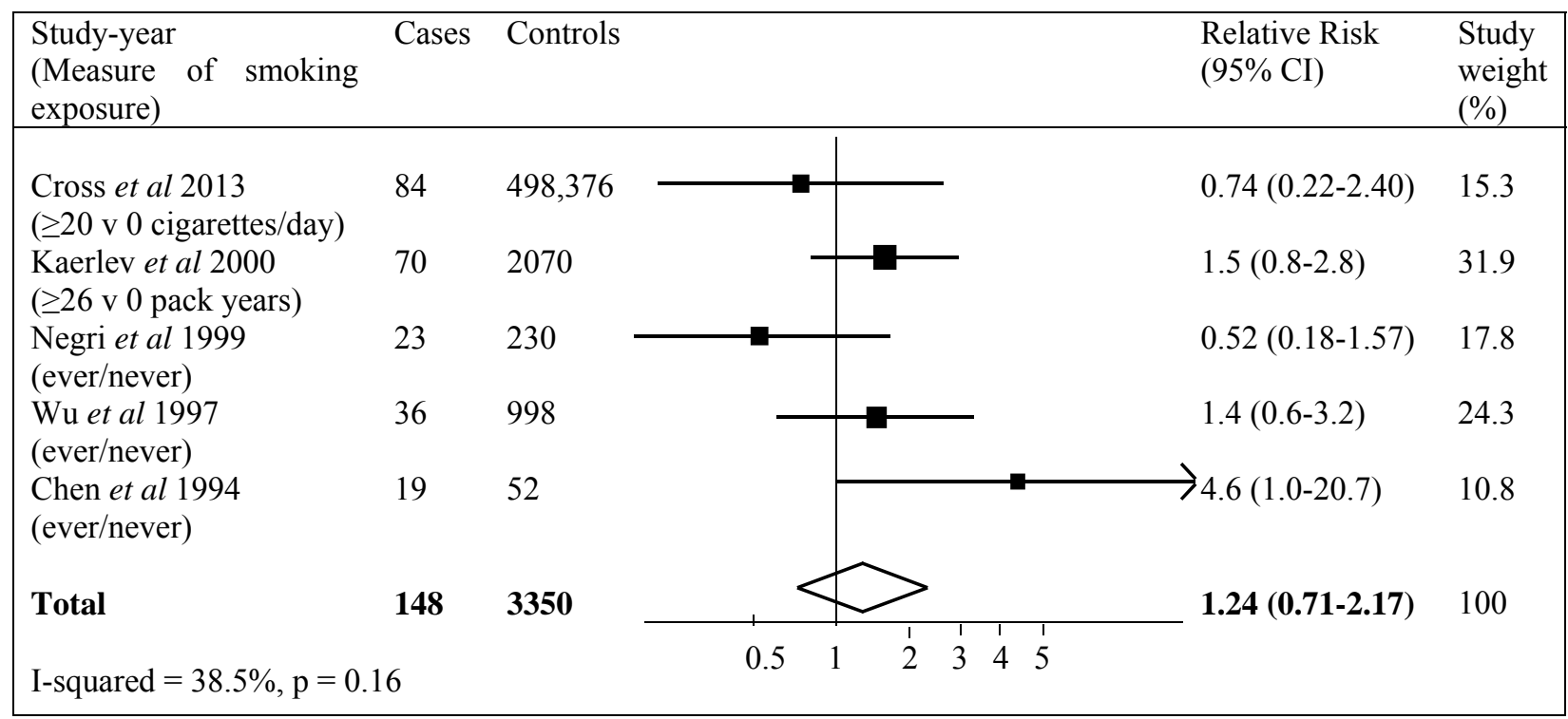


Appendix. Meta-analysis of Observational Studies in Epidemiology: MOOSE Checklist.

\begin{tabular}{|c|c|c|}
\hline \multirow{2}{*}{\multicolumn{2}{|c|}{$\begin{array}{l}\text { Criteria } \\
\text { Reporting of background }\end{array}$}} & \multirow[t]{2}{*}{ Brief description of how the criteria were handled in the review } \\
\hline & & \\
\hline$\sqrt{ }$ & Problem definition & Introduction, page 3 . \\
\hline$\sqrt{ }$ & Hypothesis statement & Introduction, page 4. \\
\hline$\sqrt{ }$ & Description of study outcomes & Methods, page 6 - 'PICOS' criteria outlined. \\
\hline$\sqrt{ }$ & Type of exposure & Methods, page 6- 'PICOS' criteria outlined. \\
\hline$\sqrt{ }$ & Type of study designs used & Methods, page 6 - 'PICOS' criteria outlined. \\
\hline$\sqrt{ }$ & Study population & Methods, page 6 - 'PICOS' criteria outlined. \\
\hline \multicolumn{2}{|c|}{$\begin{array}{l}\text { Reporting of search strategy should } \\
\text { include }\end{array}$} & \\
\hline$\sqrt{ }$ & Qualifications of searchers & Methods, page 6 . \\
\hline$\sqrt{ }$ & $\begin{array}{l}\text { Search strategy, including time } \\
\text { period included in the synthesis and } \\
\text { keywords }\end{array}$ & Methods, page 5. \\
\hline$\sqrt{ }$ & Databases and registries searched & Methods, page 5 - MEDLINE, EMBASE and Web of Science. \\
\hline$\sqrt{ }$ & $\begin{array}{l}\text { Search software used, name and } \\
\text { version, including special features }\end{array}$ & Methods, page 5. \\
\hline$\sqrt{ }$ & Use of hand searching & Methods, page 6. \\
\hline$\sqrt{ }$ & $\begin{array}{l}\text { List of citations located and those } \\
\text { excluded, including justifications }\end{array}$ & Figure 1. \\
\hline$\sqrt{ }$ & $\begin{array}{l}\text { Method of addressing articles } \\
\text { published in languages other than } \\
\text { English }\end{array}$ & Methods, page 5. \\
\hline$\sqrt{ }$ & $\begin{array}{l}\text { Method of handling abstracts and } \\
\text { unpublished studies }\end{array}$ & No searching of the grey literature performed. \\
\hline$\sqrt{ }$ & $\begin{array}{l}\text { Description of any contact with } \\
\text { authors }\end{array}$ & $\begin{array}{l}\text { One corresponding author was contacted for additional information } \\
\text { from a study, however no reply was received. }\end{array}$ \\
\hline \multicolumn{2}{|r|}{ Reporting of methods should include } & \\
\hline$\sqrt{ }$ & $\begin{array}{l}\text { Description of relevance or } \\
\text { appropriateness of studies assembled } \\
\text { for assessing the hypothesis to be } \\
\text { tested }\end{array}$ & Table 1. \\
\hline$\sqrt{ }$ & $\begin{array}{l}\text { Rationale for the selection and } \\
\text { coding of data }\end{array}$ & Methods, Table 1. \\
\hline$\sqrt{ }$ & Assessment of confounding & Table 1. \\
\hline$\sqrt{ }$ & $\begin{array}{l}\text { Assessment of study quality, } \\
\text { including blinding of quality } \\
\text { assessors; stratification or regression } \\
\text { on possible predictors of study results }\end{array}$ & Table 1. \\
\hline$\sqrt{ }$ & Assessment of heterogeneity & Figures 2-4, Table 2. \\
\hline$\sqrt{ }$ & $\begin{array}{l}\text { Description of statistical methods in } \\
\text { sufficient detail to be replicated }\end{array}$ & Methods, page 7. \\
\hline$\sqrt{ }$ & $\begin{array}{l}\text { Provision of appropriate tables and } \\
\text { graphics }\end{array}$ & Figure 1-4, Tables 1-2. \\
\hline \multicolumn{2}{|r|}{ Reporting of results should include } & \\
\hline$\sqrt{ }$ & $\begin{array}{l}\text { Graph summarizing individual study } \\
\text { estimates and overall estimate }\end{array}$ & Figures 2-4. \\
\hline$\sqrt{ }$ & $\begin{array}{l}\text { Table giving descriptive information } \\
\text { for each study included }\end{array}$ & Table 1. \\
\hline$\sqrt{ }$ & Results of sensitivity testing & Figure 3, Table 2. \\
\hline$\sqrt{ }$ & $\begin{array}{l}\text { Indication of statistical uncertainty of } \\
\text { findings }\end{array}$ & Results text, Figures 2-4, Table 2. \\
\hline \multicolumn{2}{|c|}{ Reporting of discussion should include } & \\
\hline$\sqrt{ }$ & Quantitative assessment of bias & Discussion, Strengths and Limitations, pages 12-16.. \\
\hline
\end{tabular}




\begin{tabular}{|l|l|l|}
\hline & & \\
\hline$\sqrt{ }$ & Justification for exclusion & All studies were excluded based on the pre-defined inclusion criteria. \\
\hline$\sqrt{ }$ & $\begin{array}{l}\text { Assessment of quality of included } \\
\text { studies }\end{array}$ & Results, Table 1, Discussion pages 12-16. \\
\hline Reporting of conclusions should include & $\begin{array}{l}\text { Discussion, pages 12-16. } \\
\text { explanations for observed results }\end{array}$ & Discussion, page 16. \\
\hline$\sqrt{ }$ & Generalization of the conclusions & Discussion, pages 12-16. \\
\hline$\sqrt{ }$ & Guidelines for future research & Financial support statement, page 23. \\
\hline$\sqrt{ }$ & Disclosure of funding source & \\
\hline
\end{tabular}

